problems and associated risk factors. The observations available in Italy on PPP-related poisonings and injuries suggest that greater efforts are needed to prevent these types of incidents.

\section{BE GAS SAFE PROGRAMME - REDUCING CARBON MONOXIDE POISONING}

Ashley Martin. The Royal Society for the Prevention of Accidents (RSPA)

\subsection{6/injuryprev-2016-042156.376}

Background The Chief Medical Officer of England has highlighted the need to tackle carbon monoxide (CO) poisoning with over 40 deaths and 4000 hospital attendances a year. The Be Gas Safe Programme, the first national programme to distribute CO alarms, was delivered by the Royal Society for the Prevention of Accidents (RoSPA) for the Gas Safe Charity between 2012 and 2014. The programme aimed to equip consumers to deal with dangers that lead to carbon monoxide poisoning.

Description The programme was delivered through Over 70 local partnerships across the UK who included local authorities, the NHS, fire services, housing agencies, children's and older people's charities and the police. They identified vulnerable households in their communities to receive $\mathrm{CO}$ alarms and safety information. Each partnership also received a briefing pack. A website was developed providing resources, links and useful information.

Results 13,000 CO alarms were distributed giving families protection for up to 7 years. At least 130,000 people benefitted from local education activities and media coverage reached over 3 million people. Evaluation included a survey and case studies of families whose lives have been saved either by being prompted to have their appliances serviced or because the $\mathrm{CO}$ alarm providing early warning. It showed a significant increase in awareness of the dangers and prevention measures.

Conclusions Carbon monoxide alarms are a last line of defence and are no substitute for regular servicing and good ventilation. However, research shows that combining provision of equipment with safety education is more effective than adopting one of these approaches alone. Providing practical protection for a limited number of families most at risk helped to maximise opportunities to educate a wider audience

\section{THE PRESCRIPTION DRUG EPIDEMIC IN THE UNITED STATES - EFFORTS TO IMPROVE PRESCRIBING}

Grant Baldwin, Debra Houry, Rita Noonan. Centres for Disease Control and Prevention/ National Centre for Injury Prevention and Control, USA

\subsection{6/injuryprev-2016-042156.377}

Background More than 145,000 people have died from overdoses involving prescription opioid pain relievers in the United States in the last decade and deaths have quadrupled since 1999. The quantity of opioids sold in the United States in 2011 was four times that sold in 1999. Providers wrote more than a quarter of a billion opioid prescriptions for Americans in 2012.

Description of the Problem While opioid pain relievers can and do play an important role in the management of some types of pain, the overprescribing of these powerful drugs for chronic, non-cancer pain outside of end-of- life care created and continues to fuel the epidemic. The U.S. Centres for Disease Control and Prevention (CDC) implemented a comprehensive suite of interventions to: (1) strengthen state efforts by scaling up effective, data-driven public health interventions; and (2) enhance patient safety by supplying health care providers with information, tools, and guidance for evidence-based decision making.

Results Beginning in September 2015, the CDC launched the Prevention for States program. A total of 16 states were funded to enhance and maximise state-based prescription drug monitoring programs, advance effective prevention efforts in hard hit communities, and improve health system and insurer practices to improve opioid prescribing. Early progress highlights the necessity of collaboration and that significant strides can be made when the barriers and silos within a state are eliminated. CDC also released guidelines to primary care providers for opioid prescribing for chronic pain outside of end-of-life care in January 2016. Broad dissemination is underway.

Conclusion With opioids among the most prescribed drugs in the United States, a substantial investment is needed to shift opioid prescribing to make it safer and to improve patient care. CDC's multifaceted and evidence-based interventions are making a difference. Highlights and lessons learned from CDC activities will be shared.

\section{INTERNATIONAL COMPARISONS OF DRUG-RELATED DEATHS}

Holly Hedegaard, Margaret Warner. Centres for Disease Control and Prevention/National Centre for Health Statistics, USA

\subsection{6/injuryprev-2016-042156.378}

Background In the past decade, many countries have seen a significant increase in their drug-related mortality rates. In the United States (US), drug-related deaths now outnumber deaths from any other injury cause. To better understand international differences, this study compared drug-related deaths in the US, England/Wales, Scotland and Australia, examining trends, demographic characteristics and differences in the drugs involved.

Methods Drug-related deaths were identified using public access data and reports from each country's statistical office. Cases were selected based on ICD-10 underlying cause codes of F11-16, F18-F19 (Drug abuse), X40-X44 (Accidental poisoning), X60X64 (Intentional self-poisoning), X85 (Assault by drugs) and Y10-14 (Drug poisoning of undetermined intent).

Results In 2013, the rate of drug-related deaths in the US (146 per million population) was 1.5 times the rate in Scotland, twice the rate in Australia and more than 3 times the rate in England/ Wales. In all countries, rates were higher for males than for females, with the greatest gender difference seen in Scotland. For underlying cause, in all countries, the majority of the deaths were accidental, however in England/Wales a higher percent were intentional (33\%), in Australia a higher percent had a mental/ behavioural cause (15\%) and in Scotland a higher percent were categorised as undetermined intent (17\%). In all countries, opioids including morphine, heroin and methadone were implicated in a high percent of the deaths, although drug-specific comparisons were limited due to variation by country in the completeness of the information on specific drugs.

Conclusions While similar patterns in drug-related deaths were identified, differences were also seen. The extent to which these differences are true or due to variation in death investigation, reporting and coding is unclear. Further work is needed to enhance the international comparability of mortality data on drug-related deaths. 